\title{
Endoscopic third ventriculostomy has no higher costs than ventriculoperitoneal shunt
}

\author{
Terceiro ventriculostomia endoscópica não apresenta custos mais elevados do que a \\ derivação ventrículo peritoneal
}

Benicio Oton de Lima', Riccardo Pratesi²

\begin{abstract}
Objective: To evaluate the cost of endoscopic third ventriculostomy (ETV) compared to ventriculoperitoneal shunt (VPS) in the treatment of hydrocephalus in children. Method: We studied 103 children with hydrocephalus, 52 of which were treated with ETV and 51 with VPS in a prospective cohort. Treatment costs were compared within the first year after surgery, including subsequent surgery or hospitalization. Results: Twenty (38.4\%) of the 52 children treated with VPS needed another procedure due to shunt failure, compared to 11 (21.5\%) of 51 children in the ETV group. The average costs per patient in the group treated with ETV was USD $\$ 2,177,66 \pm 517.73$ compared to USD\$2,890.68 $\pm 2,835.02$ for the VPS group. Conclusions: In this series there was no significant difference in costs between the ETV and VPS groups.
\end{abstract}

Keywords: hydrocephalus, ventriculoperitoneal shunt, neuroendoscopy, cost analysis.

\section{RESUMO}

Objetivo: Avaliar os custos da terceiro ventriculostomia endoscópica (TVE) comparada à derivação ventrículo peritoneal (DVP) no tratamento da hidrocefalia em crianças. Método: Foram estudadas 103 crianças com hidrocefalia, 52 das quais tratadas com TVE e 51 com DVP numa coorte prospectiva. Foram comparados os custos do tratamento no primeiro ano após a cirurgia, incluindo cirurgias ou internações subsequentes. Resultados: Vinte $(38,4 \%)$ das 52 crianças tratadas com DVP necessitaram de outro procedimento por disfunção da válvula, em comparação a 11 (21,5\%) das 51 crianças do grupo tratado com TVE. Os custos médios por paciente no grupo

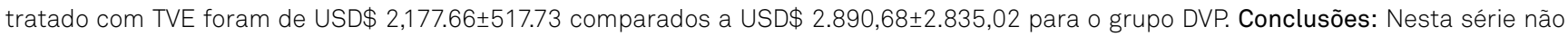
houve diferença significativa de custos entre o grupo TVE e DVP.

Palavras-chave: hidrocefalia, derivação ventriculoperitoneal, neuroendoscopia, análise de custos.

Endoscopic third ventriculostomy (ETV) and ventriculoperitoneal shunt (VPS) insertion are the most used forms of treatment of obstructive hydrocephalus in children and adults $^{1,2,3}$. Although there are many papers addressing the choice of the method of treatment of hydrocephalus ${ }^{4,5}$, there is no consensus ${ }^{6,7,8,9}$. The risk of ETV failure usually becomes gradually lower compared with the risk of VPS failure with increasing time from the surgery. Almost half of the shunt procedures performed in a hospital are shunt revisions ${ }^{10}$. The effectiveness of ETV shows a success rate extremely variable, from $30-90 \%^{11,12}$. If there is no significant difference in the outcome between the two techniques of treatment of hydrocephalus, the cost becomes an important concern, because no society has unlimited resources, and this is particularly important in the developing world ${ }^{13}$. The objective of our study was to compare the costs and outcome of treatment of obstructive hydrocephalus with ETV compared to VPS during the first year after surgery in a Brazilian Public Hospital.

\section{METHOD}

\section{Study Design}

A prospective cohort study of children who underwent initial hydrocephalus surgical treatment at the Hospital de Base do Distrito Federal (HBDF) during the years 2007 and 2008 was conducted. The children were observed during one year after the surgery. The study was approved by the Committee of Ethics and Research of the Secretary of Health of the Federal District (no. 026/07).

\footnotetext{
${ }^{1}$ Hospital de Base do Distrito Federal, Unidade de Neurocirurgia, Brasilia DF, Brazil;

${ }^{2}$ Departamento de Pediatria, Universidade de Brasilia, Brasilia DF, Brazil.

Correspondence: Benicio Oton-de Lima; SMHS, Area Especial, Q 101; 70330-150 Brasilia DF, Brasil; E-mail: otondelima@gmail.com

Conflict of interest: There is no conflict of interest to declare.

Received 29 August 2013; Received in final form 09 April 2014; Accepted 29 April 2014.
} 


\section{Patient population}

During the time of the study, 162 children were admitted for the treatment of hydrocephalus. There were different etiologies of hydrocephalus, and the choice of treatment (ETV or VPS) was at the discretion of the neurosurgeon on call. Children with severe neurological malformations such as hydranencephaly were not included. In cases with specific etiologies of hydrocephalus, such as that associated with myelomeningocele, post-infectious and post hemorrhagic, the indication of treatment was almost always VPS. These cases were also excluded from the study.

The cohort studied consisted of 103 children, 52 treated with VPS and 51 treated with ETV. Information recorded included age, sex, etiology of hydrocephalus, imaging, surgery (ETV or VPS) and operative complications, length of hospital stay after the surgery, late complications, hospitalizations for failures of VPS or ETV up to one year after the first surgery, total number of in-patient hospital days due to failure, number of new surgeries needed for correction of the initial failure, follow up during one year after the first surgery, head circumference at surgery and after one year, improvement in neurological status after one year, and total costs paid by the Brazilian Government. Cases of early failure of the procedure were counted as a new admission even when occurred during the first week after surgery.

The ETV was conducted using a rigid endoscope ${ }^{14}$ inserted in the lateral ventricle (usually from the right) free hand. The floor of the third ventricle was perforated using a 4 French balloon catheter, midway between the mammillary bodies and the infundibular recess in the midline, and was considered successful if the Liliequist membrane was opened, and the surgeon could see the basilar tip or its branches. The VPS were performed with the use of a fixed pressure valve available at the moment of the surgery (Ventura Biomédica, Sao José do Rio Preto, Brazil, or Phoenix Biomedical, PA, USA).

The number of hospital days was counted after the first surgery for hydrocephalus. The failure of the procedure (ETV or VPS) was defined by any subsequent surgery for cerebrospinal fluid (CSF) diversion ${ }^{15}$ or death related do hydrocephalus. The head circumference was considered by percentile, according to the child's age. The neurological status was evaluated using the Denver Scale adapted for children up to 7 years of age. For those older than 7 years the Health Utilities Index ${ }^{16}$ was used. The children were examined prior to surgery and at one-year follow up and the exams compared.

The costs of the treatment of the children with hydrocephalus in our series were calculated taking into account the values reimbursed by the Brazilian government. The Brazilian Health Care System pays for the health care for all Brazilian citizens. Most of the people who seek treatment in Public Hospitals in Brasilia are low-income, and do not have a private health insurance. The Unified Health System of the Brazilian Government pays a total amount of \$ 1,760.89 (all monetary units are given in US dollars for the year 2008) for each patient treated with ETV. In this amount is included all the hospitalization expenses for a period of up to 6 days. The payment is made by the procedure per patient, so that hospitals try to optimize their costs, reducing hospitalization time, and trying to avoid complications. For those treated with VPS, the amount of \$ 833.73 is paid for the surgery and hospital costs, and an extra $\$ 469.88$ is paid for the shunt valve and catheters. In this study, the costs were calculated for each patient according to the procedure, imaging tests, hospital stay, and complications. If the child needed a new surgery for treatment of VPS or ETV failure, the costs of this treatment were added.

Data were analyzed using SPSS Advanced Statistics 20.0 (SPSS Inc., Chicago, IL, USA).

\section{RESULTS}

The group was composed of 77 (47.5\%) girls and 85 $(52.5 \%)$ boys. There were different etiologies of hydrocephalus (Table 1). The cohort study group was composed of 103 hydrocephalic children with a mean age of $24.6 \pm 25.2$ months, 52 of them treated with VPS (mean age 17.6 \pm 18.3 months) and 51 treated with ETV (mean age $32.4 \pm 29.5$ months). The mean postoperative hospital stay was $2.1 \pm 0.8$ days, ranging from 1-4 days, and was similar for both groups (ETV 2.24 \pm 0.6 days and VPS $2.06 \pm 0.8$ days).

From the 52 treated with VPS, 20 (38\%) showed failure, and it was necessary to perform 61 new operations, ranging from 1 to 10 new surgeries per child. From the 51 treated with ETV, 11 (21.5\%) showed failure, and were reoperated 10 times. One child with cerebrospinal fluid (CSF) leak was managed conservatively. The causes of failure of the first surgical treatment for hydrocephalus are listed on Table 2.

Some complications did not need surgical correction, such as positional deformities in the skull due to CSF over drainage in nine children treated with VPS, none was observed in those treated with ETV. In two children in the

Table 1. Etiologies of hydrocephalus and surgery.

\begin{tabular}{lccc} 
Etiology & VPS & ETV & Total \\
\hline Neurocysticercosis & 0 & 1 & 1 \\
Post traumatic & 3 & 2 & 5 \\
Post infectious & 8 & 1 & 9 \\
Dandy Walker Malformation & 8 & 1 & 9 \\
Posterior fossa tumor & 4 & 6 & 10 \\
Post hemorrhagic & 16 & 0 & 16 \\
Myelomeningocele & 23 & 1 & 24 \\
Congenital obstructive & 45 & 43 & 88 \\
Total & 107 & 55 & 162 \\
\hline
\end{tabular}

VPS: ventricle peritoneal shunt; ETV: endoscopic third ventriculostomy. 
Table 2. Causes of failure of treatment.

\begin{tabular}{lcc}
\hline & VPS & ETV \\
\hline CSF fistula & 1 & 1 \\
Infection & 7 & 0 \\
Obstruction & 12 & 10 \\
\hline VPS: ventricle peritoneal shunt; ETV: endoscopic third ventriculostomy.
\end{tabular}

VPS group was noted temporary accumulation of CSF in the valve path, but as there was good control of the hydrocephalus, they were treated conservatively. In the ETV group, one child had transient hemiparesis and another had acute hydrocephalus almost 10 months after the procedure and died. The average head circumference of the children in the VPS group was in the percentile $93.8 \pm 15.7$ and in the ETV group was $91.1 \pm 12.4$. The head circumference one year after the first surgery was in the $50.7 \pm 41.2$ percentile in the VPS group and $76.9 \pm 17.6$ percentile in the ETV group. No difference in neurological status improvement was noted between the VPS and ETV group.

The survival rate of the CSF diversion at one year, shown in Figure, was $78.4 \pm 5.8 \%$ for ETV and $61.5 \pm 6.7 \%$ for VPS. Despite the trend toward greater survival time of ETV compared to VPS, there is no statistical significance by the Log Rank and Breslow tests of equality of survival distributions.

The average costs paid for the treatment of hydroceph-

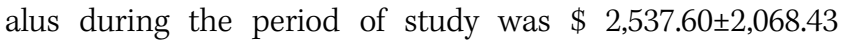
ranging from $\$ 1,357.75$ to $\$ 12,923.15$. The average cost for treatment of hydrocephalus with VPS was $\$ 2,890.69 \pm 2,835.02$ and for those treated with ETV was $\$ 2,177.60 \pm 517.73$. There is no statistically significant difference between the two groups, but in the present series there is a trend to lower costs in the ETV group.

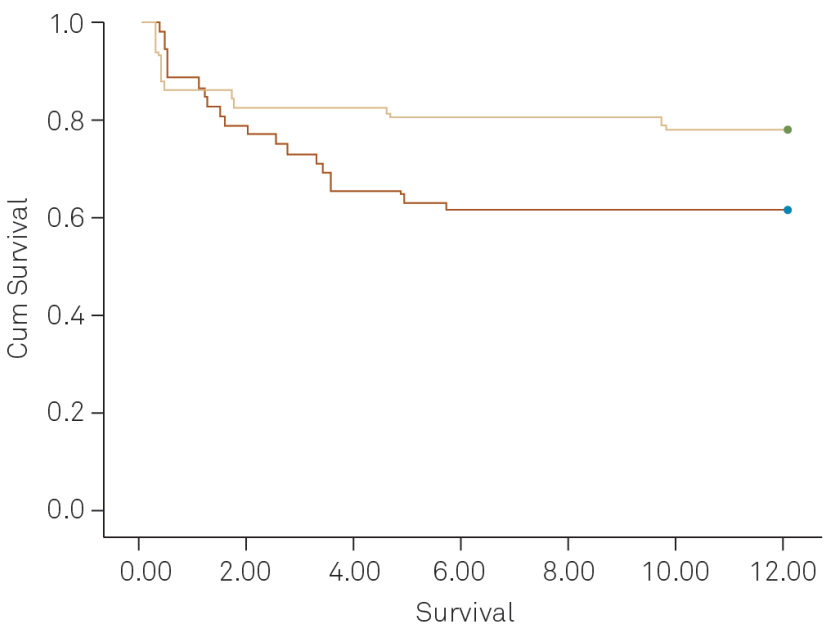

VPS: ventricle peritoneal shunt; ETV: endoscopic third ventriculostomy.

Figure. Kaplan Meier curve for ETV or VPS. ETV survival curve is shown in dotted line and VPS survival curve in continuous line. VPS: ventricle peritoneal shunt; ETV: endoscopic third ventriculostomy.

\section{DISCUSSION}

Pediatric hydrocephalus places a substantial burden on patients and the health care system. Since the introduction of ETV in the 1990s, this technique has rapidly gained new enthusiasts and was indicated as the procedure of choice in the treatment of obstructive hydrocephalus ${ }^{17,18,19}$, avoiding the fear of VPS malfunction and need for further surgery. Probably a child with a shunt malfunction generates more emergency visits, creates more anxiety in parents and physicians, and consumes more resources than all other pediatric neurosurgery problems ${ }^{20,21}$. The choice between VPS and ETV should take into account the clinical outcomes and the expenditures for each surgical procedure ${ }^{22}$.

As described before in previous studies ${ }^{8}$, we did not observe difference in outcome in children with hydrocephalus treated with ETV or VPS. There was no difference in postoperative hospital stay between the two groups, and both procedures were well tolerated by children. The number of reoperations was higher in the VPS group, and two children have been submitted to 10 new surgical procedures. Considering the emotional burden for the child and for parents for every surgery, it is thought that the emotional suffering is greater in this group than with ETV, which required a smaller number of reoperations ${ }^{23,24,25,26}$. In our study CSF infection was observed only in the VPS group. Whereas ventriculitis may impair cognitive function of children ${ }^{26}$, this is a factor that must be taken into consideration when choosing between ETV and VPS in the initial treatment of obstructive hydrocephalus. The VPS led to a faster control of large head circumference, but otherwise caused an increased frequency of positional deformities in the skull. This data needs to be further studied by comparing groups of infants treated with ETV and VPS. Since there is a tendency to treat older children with ETV, it is possible that this issue will be not adequately answered. A complication found only in the group treated with ETV was transient neurological deficit and late death. This is a rare complication and there is report of only few cases in the world ${ }^{27}$. We observed a continuous decrease in the Kaplan-Meier survival curve for the patients treated with VPS in the first year of follow up. In the ETV group there was a rapid decrease after the procedure followed by a more constant curve.

This is the first Brazilian study of the economic costs associated with hydrocephalus. Comparing the costs of ETV with VPS in a public hospital, we noted a tendency to higher costs in the VPS group with passing of time, although this difference was not statistically significant, as have been related before ${ }^{22}$. When dealing with costs for chronic childhood illness like hydrocephalus, it should be noted that there are transportation costs, access to services, and usually there is a decrease in the family income $^{23}$. The stress and worry caused by short monetary 
resources may have effects on the well being of the whole family ${ }^{25}$.

The initial costs of the treatment of hydrocephalus paid by public money were higher in the ETV group than in the VPS group. However, when comparing costs with one year follow up, the final costs are reversed, with more costly treatment with VPS than with ETV. It should be noted that this series shows a tendency, but the numbers are not statistically significant.
In this series, the choice of the surgical technique for the treatment of obstructive hydrocephalus could not be determined by the clinical results, since these results were similar. Thus the financial aspect becomes important and there was a tendency after one year of the surgery to lower expenses when the hydrocephalus was treated with ETV, although without statistical significance. This trend suggests that Public Resources should continue to be used in the endoscopic treatment of hydrocephalus.

\section{References}

1. Feng $\mathrm{H}$, Huang $\mathrm{G}$, Liao X, et al. Endoscopic third ventriculostomy in the management of obstructive hydrocephalus: an outcome analysis. J Neurosurg 2004;100:626-633.

2. Hellwig D, Grotenhuis JA, Tirakotai W, et al. Endoscopic third ventriculostomy for obstructive hydrocephalus. Neurosurg Rev 2005;28:1-34.

3. Javadpour M, Mallucci C, Brodbelt A, Golash A, May P. The impact of endoscopic third ventriculostomy on the management of newly diagnosed hydrocephalus in infants. Pediatr Neurosurg 2001;35:131-135.

4. Drake JM, Kulkarni AV, Kestle J. Endoscopic third ventriculostomy versus ventriculoperitoneal shunt in pediatric patients: a decision analysis. Childs Nerv System 2009;25:467-472.

5. Tamburrini G, Pettorini BL, Massimi L, Caldarelli M, Di Rocco C. Endoscopic third ventriculostomy: the best option in the treatment of persistent hydrocephalus after posterior cranial fossa tumor removal? Childs Nerv Syst 2008;24:1405-1412.

6. Sgouros S, Kulkarni AV, Constantini S. The international infant hydrocephalus study: concept and rational. Childs Nerv Syst 2006;22:338-345

7. Sacko O, Boetto S, Lauwers-Cances V, Depuy M, Roux F-Egy. Endoscopic third ventriculostomy: outcome analysis in 368 procedures. J Neurosurg Pediatr 2010;5:68-74.

8. Kulkarni AV, Hui S, Shams I, Donnelly R. Quality of life in obstructive hydrocephalus: endoscopic third ventriculostomy compared to cerebrospinal fluid shunt. Childs Nerv Syst 2010;26:75-79.

9. Di Rocco C, Massimi L, Tamburrini G. Shunts vs endoscopic third ventriculostomy in infants: are there different types and/or rates of complications? Childs Nerv Syst 2006;22:1573-1589.

10. Patwardhan RV, Nanda A. Implanted ventricular shunts in the United States: the billion-dollar-a-year cost of hydrocephalus treatment. Neurosurgery 2005;56:139-145.

11. Bouras T, Sgouros S. Complications of endoscopic third ventriculostomy: a systematic review. Acta Neurochir 2012;113(Suppl):S149-S153.

12. Durnford AJ, Kirkham FJ, Mathad N, Sparrow OCE. Endoscopic third ventriculostomy in the treatment of childhood hydrocephalus: validation of a success score that predicts long-term outcome. J Neurosurg Pediatrics 2011;8:489-493.

13. Warf BC. Hydrocephalus in Uganda: the predominance of infectious origin and primary management with endoscopic third ventriculostomy. J Neurosurg Pediatr 2005;102:1-15
14. Jallo Gl, Kothbauer KF, Abbott R. Endoscopic third ventriculostomy. Neurosurg Focus 2005;19:1-4.

15. Drake JM. Endoscopic third ventriculostomy in pediatric patients: the Canadian experience. Neurosurgery 2007;60:881-886.

16. Torrance GW, Feeny DH, Furlong WJ, Barr RD, Zhang Y, Wang Q. Multiattribute preference functions for a comprehensive health status classification system: Health Utilities Index Mark 2. Med Care 1996;34:702-722.

17. Peretta P, Ragazzi P, Galarza M, et al. Complications and pitfalls of neuroendoscopic surgery in children. I Neurosurg 2006;105(Suppl):S187-S193.

18. de Ribaupierre S, Rilliet B, Vernet O, Regli L, Villemure J-G. Third ventriculostomy vs ventriculoperitoneal shunt in pediatric obstructive hydrocephalus: results from a Swiss series and literature review. Childs Nerv Syst 2007;23:527-533.

19. Brockmeyer D, Abtin K, Carey L, Walker ML. Endoscopic third ventriculostomy: an outcome analysis. Pediatr Neurosurg 1998;28:236-240

20. Drake J. Shunt failure. J Neurosurg Pediatr 2010;6:316-317.

21. Chern JJ, Macias CG, Jea A, Curry, DJ, Luerssen TJ, Whitehead WE. Effectiveness of a clinical pathway for patients with cerebrospinal fluid shunt malfunction. J Neurosurg Pediatr 2010;6:318-324.

22. Garton HJL, Kestle JRW, Cochrane DD, Steinbok P. A cost-effectiveness analysis of endoscopic third ventriculostomy. Neurosurgery 2002;51:69-78.

23. Shannon CN, Simon TD, Reed GT, Franklin FA, Kirby RS, Kilgore ML, Wellons III JC. The economic impact of ventriculoperitoneal shunt failure. J Neurosurg Pediatr 2011;8:593-599.

24. Kuhlthau K, Hill KS, Yucel R, Perrin JM. Financial burden for families of children with special health care needs. Matern Child Health $J$ 2005;9:207-218.

25. Lindley LC, Mark BA. Children with special health care needs: impact of health care expenditures on family financial burden. J Child Fam Stud 2010;19:79-89.

26. Kanev PM, Sheehan JM. Reflections on shunt infection. Pediatr Neurosurg 2003;39:285-290.

27. Drake J, Chumas P, Kestle J, et al. Late deterioration after endoscopic third ventriculostomy: additional cases and review of the literature. J Neurosurg 2006;105(Suppl):S118-S126. 